\title{
Pediatric Sepsis Markers: Interleukins and Others
}

\author{
B. Polic ${ }^{1} \quad$ P. Dahlem ${ }^{2} \quad$ M. Saraga ${ }^{1}$ \\ 1 Department of Pediatrics, University Hospital of Split, Split, Croatia \\ ${ }^{2}$ Department of Pediatrics, Medical Center Coburg, Academic \\ Hospital of the University of Split, Coburg, Germany
}

\begin{abstract}
Address for correspondence B. Polic, MD, PhD, Department of Pediatrics, University Hospital of Split, Spinciceva 1, 21000 Split, Croatia (e-mail: branka.polic1@gmail.com).
\end{abstract}

\begin{abstract}
Keywords

- sepsis

- immune response

- cytokines

- other biomarkers

Cytokines are a very important part in the regulation of immune response in sepsis. They are cellular signaling proteins whose production is a result of activation of specific receptors. Variations in the genes encoding cytokines have a significant role in interindividual susceptibility to sepsis and its severity, and their function may be modulated by age, gender, and some environmental factors. Cytokines are classified into the subsets of proinflammatory, anti-inflammatory, and multiple function cytokines. Regulated balance between proinflammatory cytokines, anti-inflammatory cytokines, and soluble inhibitors of proinflammatory cytokines is important for eliminating pathogens and reducing inflammation. High levels of some cytokines, such as tumor necrosis factor- $\alpha$, interleukin (IL)-1, and IL- 6 , determine the course of disease and outcome in sepsis. Likewise, numerous other biomarkers may be potential indicators of sepsis, but none has been routinely used. The best approach to the diagnosis of sepsis is the combination of different biomarkers.
\end{abstract}

\section{Introduction}

Bacterial sepsis is a complex and dynamic clinical syndrome that is a result of a systemic inflammatory response to bacteria and their products and has a high mortality rate. ${ }^{1}$ Markers that can identify high-risk patients are crucial for early detection of sepsis as well as for monitoring the course of disease. Cytokines are a very important part of the development of sepsis, particularly for their role in the regulation of immune response. They are cellular signaling proteins whose production is a result of activation of receptors such as Toll-like receptors (TLRs), retinoid acid inducible protein 1-like receptors and nucleotidebinding oligomerization domainlike receptors that are present on the cell surface and transfer specificity in the innate immune response. Activation of these receptors by pathogens results in production of cytokines, as well as coagulation proteins and complement. Various researches suggest that not only cytokines by themselves but also the variations in the genes encoding cytokines are important and have a significant role in interindividual susceptibility and severity to sepsis. ${ }^{2,3}$ Also, during the progression of sepsis, the inflammatory cytokines may be modulated by age, gender, and some environmental factors. ${ }^{4}$

Cytokines are small protein mediators with low molecular weights $(<40 \mathrm{kDa})$, which activate and differentiate the immune response. Cytokines are classified into the subsets of proinflammatory, anti-inflammatory, and multiple function cytokines. Tumor necrosis factor- $\alpha$ (TNF- $\alpha$ ), inducible protein-10 (IP-10), interleukin (IL)-2, IL-6, IL-8, IL-12, and IL-17 are proinflammatory cytokines. Proinflammatory response includes activation of many immunological pathways where release of specific cytokines represents "cytokine cascade." Anti-inflammatory cytokines are IL-4, IL-10, IL-1 receptor $\alpha$, TNF soluble receptor, and transforming growth factor- $\beta 2$ (TGF- $\beta 2)$. These cytokines strive to restore immunological received

December 5, 2016 accepted after revision March 8, 2017
Issue Theme Pediatric Sepsis Biomarkers; Guest Editors: Peter Dahlem, MD, PhD, Marijan Saraga, MD, PhD, Walter L. Strohmaier, MD, PhD

DOI https://doi.org/ 10.1055/s-0037-1603896. ISSN 2474-5871.
Copyright @ 2017 Georg Thieme Verlag KG Stuttgart · New York
License terms

(®) $\Theta \circledast$ 
balance. Multiple function inflammatory cytokines include IL-1 $\beta$, IL-3, monocyte chemoattractant protein-1, soluble CD40 ligand, and growth factors such as granulocyte-colony stimulating factor. Their secondary mediators are thromboxanes, nitric oxide, leukotrienes, prostaglandins, platelet-activating factor, and complements. ${ }^{5,6}$ The inflammatory response, apart from cytokines, includes many biomarkers such as acutephase proteins release, coagulation factors, vascular endothelium products, leukocytes, histocytes, and platelets. ${ }^{7}$ As it is known, what is important in sepsis is innate immune response, which is triggered by bacterial infection. In the past, sepsis was explained as an exacerbated release of proinflammatory cytokines, such as TNF- $\alpha$, IL-1, IL-6, IL-12, macrophage migration inhibitory factor (MIF), and interferon- $\gamma($ IFN- $\gamma$ ), but recently it has been shown that compensatory anti-inflammatory response that occurs after hyperinflammatory period is also important. It is known that the proinflammatory response is antagonized by anti-inflammatory cytokines, including IL-10, IL-4, and TGF- $\beta$, which attempt to restore immunological balance. ${ }^{8,9}$ Most adverse effects of sepsis such as systemic inflammatory response syndrome (SIRS), disseminated intravascular coagulation (DIC), septic shock, complement activated response syndrome, and multiple organ dysfunction syndrome are associated with an imbalance in the production of proinflammatory mediators as well as counterweight synthesis of anti-inflammatory cytokines. Regulated balance between proinflammatory cytokines, anti-inflammatory cytokines, and soluble inhibitors of proinflammatory cytokines, such as soluble TNF receptors (sTNFRs), IL-1 receptor antagonist (IL-1Ra), and IL-1 receptor type II (IL-1R2), is important for eliminating pathogens and reducing inflammation. ${ }^{10}$ It is also known that high levels of some cytokines, such as TNF- $\alpha$, IL- 1 , and IL-6, determine the course of disease and outcome in sepsis. ${ }^{11}$

\section{Interleukins}

TNF- $\alpha$ is a $17-\mathrm{kDa}$ protein derived predominantly from macrophages but also partly from nonimmune cells such as fibroblasts. ${ }^{12}$ The release of TNF- $\alpha$ begins within 30 minutes after the stimulus, following gene transcription and RNA (ribonucleic acid) translation. TNF- $\alpha$ acts through specific transmembrane receptors, named TNF receptor (TNFR) 1 and TNFR2, ${ }^{13}$ and activates immune cells as well as the release of other immunoregulatory mediators. In experimental endotoxemia, the circulating levels of TNF- $\alpha$ reach the peak in one and half hour after stimulus. ${ }^{14}$ The release of TNF- $\alpha$ causes vasodilatation and increases vascular permeability, which may lead to systemic edema. Decreased blood volume and hypoproteinemia can lead to progression of shock. Leukocyte and platelet adhesion with depletion of coagulation factors may lead to DIC with multipleorgan failure and death. ${ }^{15}$ In experimental animals, the injection of TNF- $\alpha$ causes a syndrome that looks like septic shock, ${ }^{16}$ and infusion of recombinant TNF- $\alpha$ into humans results in SIRS. ${ }^{17}$ TNF- $\alpha$ was one of the first mediators identified in inflammation $^{18}$ and has been suggested as a marker for the prediction of early sepsis in children, especially when used with IL-6. ${ }^{19}$ But due to the short half-life ( $\sim 70$ minutes) and its interaction with soluble receptor, its detection is exceptionally difficult. ${ }^{20}$
IL-1 is a proinflammatory cytokine that is released from activated macrophages, as TNF- $\alpha$, and signaled through two receptors, IL-1 receptor type I and IL-1R2, which has comparable effects on immune cells. ${ }^{21}$ IL-1 family includes two agonists (IL- $1 \alpha$ and IL-1 $\beta$ ) and one antagonist (IL-1Ra) as mediators of immune response to sepsis. ${ }^{3}$ IL-1Ra levels reach peak 2 to 4 hours after application of endotoxin and remain elevated for more than 24 hours. It has a longer half-life than IL-6 and is potentially a better biomarker in the diagnosis of sepsis. ${ }^{22}$ IL-1 induces coagulation and extravasation of inflammatory cells, and persistently elevated levels can be correlated with multiple-organ failure and worse prognosis in adults. ${ }^{23}$

TNF- $\alpha$ and IL- 1 synergistically induce a shocklike state, which is characterized by vascular permeability, severe pulmonary edema, and hemorrhage. ${ }^{24}$ Also, they are responsible for fever and belong to a group of pyrogenic cytokines. ${ }^{25}$ TNF- $\alpha$ and IL- 1 act on various cells such as macrophages, endothelial cells, and neutrophils. TNF- $\alpha$ promotes the activation and differentiation and prolongs survival of macrophages. ${ }^{26}$ In endothelial cells, TNF- $\alpha$ augment the expression of intercellular adhesion molecule-1, vascular cell adhesion molecule- 1 , and chemokines. ${ }^{27}$ Also, TNF- $\alpha$ promotes neutrophils extravasation into tissues and upregulates action on endothelial expression of procoagulant. ${ }^{18}$ TNF- $\alpha$ and IL-1 activate macrophages to secrete other proinflammatory cytokines (IL-6, IL-8, and MIF) and lipid mediators. ${ }^{9}$

Soluble cytokine receptors and receptor antagonists, such as sTNFRs, IL-1R2, and IL-1Ra, modulate the actions of TNF- $\alpha$ and IL-1. Plasma concentrations of sTNFRs correlate not only with disease severity but also with mortality. ${ }^{28}$ As opposed to that, administration of IL-1Ra increased survival and in that way suggests positive therapeutic effect for IL-1Ra. ${ }^{29}$

On top, TNF- $\alpha$ and IL- 1 are involved in many other inflammatory diseases such as rheumatoid arthritis, osteoarthritis, and atherosclerosis. ${ }^{30-32}$

IL-6 is a glycoprotein produced by macrophages, lymphocytes, fibroblasts, endothelial dendritic, and smooth muscle cells. ${ }^{33,34}$ During the acute phase of an infection, B and $\mathrm{T}$ lymphocytes are stimulated to produce IL-6. IL-6 activates the coagulation system, and modulates hematopoiesis as well as stimulates the release of TNF- $\alpha$ and IL-1. IL-6 is an early marker of sepsis in neonates and children and is more potent than C-reactive protein (CRP). ${ }^{35}$ IL-6 has high sensitivity and specificity in predicting positive cord blood culture in newborns with premature rupture of membranes, ${ }^{36}$ and plasma levels of IL-6 of $160 \mathrm{pg} / \mathrm{mL}$ are $100 \%$ sensitive for the diagnosis of early onset sepsis in neonates. The combination of IL-6, TNF- $\alpha$, and CRP leads to sensitivity and negative predictive values that increase close to $90 \%$ in diagnosis early onset neonatal sepsis. ${ }^{37}$ IL-6 mediates a systemic reaction to an inflammatory stimulus, that is, fever, leukocytosis, and the release of hepatic acute-phase proteins such as CRP, complement components, fibrinogen, and ferritin. ${ }^{38}$

IL-8 is a proinflammatory cytokine and a potent neutrophil activating agent that is released from monocytes, endothelial cells, and neutrophils in response to IL- 1 and TNF- $\alpha$. IL- 8 also regulates leukocyte migration. It is a frequently studied cytokine as a marker of neonatal sepsis. IL- 8 peaks 2.5 to 3 hours 
after stimulus. In one study, elevated levels of IL-8 predict organ failure in adults with septic shock. ${ }^{39}$ Contrary to this, another study indicates that IL-8 is not a powerful biomarker in adults, ${ }^{40}$ whereas some studies in children have shown that IL-8 can serve as an indicator of outcome in children with septic shock. ${ }^{41}$ IL-8 was identified as one of 34 genes that were increased in nonsurvivors relative to survivors and that was confirmed with involving genome-wide expression profiling in pediatric septic shock using RNA from blood samples supply within 24 hours of admission. ${ }^{42} \mathrm{~A}$ serum IL-8 level of $220 \mathrm{pg} / \mathrm{mL}$ or less measured within first 24 hours in children with septic shock may predict survival with probability of $95 \%$. Also, IL-8 was increased in nonsurvivors relative to survivors, based on 28-day mortality in sepsis. This indicates that IL-8 elevation correlates with a more severe condition. ${ }^{43}$ IL- 8 can also be produced in placental or fetal cells in infectious started in the uterus $^{44}$ and, as IL-6, is a useful biomarker of early onset neonatal sepsis with sensitivity of $90 \%$ and specificity between 75 and $100 \%$. The fact that serum concentration of IL-8 rises rapidly after an infection (within 2-4 hours) makes it useful as an early marker of sepsis. ${ }^{45}$ In recent investigations, high value of IL-8 in a very low birth weight premature infants with clinical signs of early infection may be associated with the development of retinopathy. ${ }^{46}$

IL-10 is an anti-inflammatory cytokine and is produced by monocytes, macrophages, natural killer (NK) cells. and B and T lymphocytes. ${ }^{47}$ IL-10 suppresses the production of proinflammatory mediators, and in an experimental model, administration of recombinant murine IL- 10 protects the mice from lethal endotoxemia. ${ }^{48} \mathrm{IL}-10$ is structurally related to the IL-6 cytokine family, although its function is opposite. High IL-6:IL-10 ratio in sepsis was found in patients with a worse prognosis. ${ }^{49}$ Recently, it was investigated that IL-10 might regulate the transition from early reversible sepsis to late irreversible septic shock and that polymorphisms in the IL-10 gene promotor affect sepsis susceptibility. ${ }^{50}$

IL-12, initially called NK cell stimulatory factor or cytotoxic lymphocyte maturation factor, is a protein composed of two polypeptide subunits, p39 and p24. It plays a key role in the differentiation of Th1 and induces the production of IFN- $\gamma$. Recently, IL-12 was characterized as a major cytokine in the pathogenesis of gram-negative endotoxemia in mice. ${ }^{51}$ Also, IL-12 stimulates the differentiation of naive $\mathrm{CD} 4^{+} \mathrm{T}$-cells and protects them from antigen-induced apoptotic death. ${ }^{52}$ In humans, a selective defect in preoperative monocyte IL-12 production disrupts the host defense against postoperative infections and increases the risk of lethal sepsis. ${ }^{53}$ IL-12 was measured in newborns at the time when sepsis was first suspected clinically and was higher in patients with sepsis than in those without sepsis. ${ }^{54}$

IL-18 is a proinflammatory cytokine produced by activated macrophages that are included in the induction of cellmediated immunity. Elevated serum levels of IL-18 are associated with poor clinical outcome in severe sepsis. IL-18 may play an important role in the pathogenesis of idiopathic thrombocytopenic purpura. Several studies demonstrated that IL-18, as novel prognostic cytokine, is involved in severe sepsis with thrombocytopenia. ${ }^{55}$ Also, a group of authors reported that IL-18, as well as seven other serum markers, was elevated in preterm infants with infection, ${ }^{56}$ whereas the other authors demonstrated that IL-18 had no diagnostic ability in neonates. ${ }^{57}$

TGF- $\beta$ is an important anti-inflammatory cytokine that plays a role in sepsis-induced immunosuppression, tissue repair, and fibrosis..$^{58}$ Except suppression of the release of proinflammatory mediators and stimulation production of immunosuppressive factors such as sTNFRs and IL-1Ra, TGF- $\beta$ also inhibits IL-2 secretion and T-lymphocyte proliferation. ${ }^{59}$ Recent data suggests that TGF- $\beta$ may have cardioprotective effects with reverse the depression of myocardiac contraction induced by proinflammatory cytokines in patients with septic shock. ${ }^{60}$ Animal models showed that treatment with TGF- $\beta$ blocked endotoxin improved survival in Salmonella typhosa endotoxininduced septic shock. ${ }^{61}$ Notwithstanding, TGF- $\beta$ levels were shown to peak early in disease, and they did not correlate strongly with severity of disease nor with the prognosis. ${ }^{62}$

IL-4 is a cytokine with many immunoregulatory functions, and the most important is regulation of $\mathrm{T}$ lymphocyte differentiation. ${ }^{63}$ IL-4 is a cytokine produced by lymphocytes and its important role is suppressing the secretion of monocytederived proinflammatory cytokines. ${ }^{64}$ Although, studies suggest that IL-4 plays an important role in the pathogenesis of sepsis, its precise role is unknown. It was reported that in humans, the messenger RNA expression of IL-4 was associated with survival of patients with severe sepsis, but the plasma levels of IL-4 on the day of admission did not differ between survivors and nonsurvivors. ${ }^{65}$

Recent studies investigated IL-3, a novel mediator that can potentiate inflammation in sepsis. In a mouse model of abdominal sepsis, it has been shown that innate response activator $B$ cells produce IL-3, which induces myelopoiesis of Ly-6C (high) monocytes and neutrophils and originated a cytokine storm. High plasma IL-3 levels were associated with high mortality. Therefore, IL-3 is identified as an orchestrator of emergency myelopoiesis and can be a new therapeutic target for treating sepsis. ${ }^{66}$

\section{Other Biomarkers}

CD64 is a neutrophil cell surface marker, known as FcyR1. It is a receptor on the neutrophil and its function is to bind the Fc portion of IgG (hence $\gamma$ ) antibodies. Those antibodies facilitate bacterial opsonization and phagocytosis. The level of CD64 is measured by the flow cytometric analysis of blood samples, and in pediatrics, CD64 has been investigated primarily to identify premature and term neonates with sepsis. Some authors showed that CD64 was elevated in children with documented infections, but was unable to distinguish between viral and bacterial infections. They also found that procalcitonin (PCT) was more specific and CRP was more sensitive than CD64. ${ }^{67,68}$ In a small group of older children, it has been shown that CD64 was able to distinguish between sepsis and SIRS better than CRP and PCT, especially when combined with the lipopolysaccharide-binding protein (LBS), ${ }^{69}$ but much more investigation needs to be done to determine the clinical utility of this biomarker. ${ }^{70}$ One of recent 
studies confirmed CD64 utility as a good marker of bacterial sepsis since it was found to have mean sensitivity of $71 \%$ and a mean specificity of $87 \%{ }^{71}$

The expression of $\mathrm{CD} 11 \mathrm{~b}$ on neutrophils in sepsis may predict the development of organ failure and poor prognosis in patients with septic shock. ${ }^{72}$ One study demonstrated that CD11b expression has increased in some infants from the infection group up to 3 days before the onset of symptoms. This suggested that CD11b level may enable an early diagnosis of infection. ${ }^{73}$ Some authors reported that neutrophil and monocyte CD11b expressions were significantly elevated in infected neonates. The neutrophil CD11b had a sensitivity of $66 \%$ and specificity of $71 \%$, whereas monocyte CD11b had a sensitivity of $70 \%$ and specificity of $62 \%$ for detecting neonatal infection. ${ }^{74}$ Also, CD15s is a potentially valuable biomarker of severe bacterial infection in infants. ${ }^{71}$

Lactate level is an important biomarker that can distinguish sepsis from septic shock and can predict the prognosis. Initially, serum lactate was recognized and used as an indicator of tissue hypoxia. Serum lactate levels rise when lactate production outstrips the body's ability to metabolize it. Also, an increase in lactate occurs when there is a decrease in its metabolic capacity, which is often seen in SIRS. The majority of researches, which found increased serum lactate in patients with sepsis, have been conducted on adults. ${ }^{75,76}$ It has been found that the patients with increased serum lactate in sepsis were sicker and had increased mortality, and it was also observed that patients whose lactate levels decreased with proper therapy had better outcomes. ${ }^{77,78}$ Related to this, lactate level was used as a diagnostic, monitoring, and prognostic biomarker. The serum level of lactate in septic children may identify a population at higher risk for severe outcomes. In children with SIRS, a single elevated lactate level increases risk of organ dysfunction several times. Since elevated lactate levels correspond with organ dysfunction and the need for resuscitative therapies, it may be an early indicator of resuscitation requirement in children. ${ }^{79}$

CCL3 (also known as macrophage inflammatory protein-

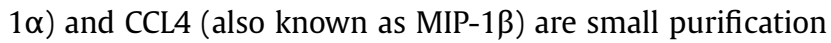
molecules that lead to increased infiltration of inflammatory cells. CCL3 belongs to the $\mathrm{C}-\mathrm{C}$ chemokine family that is secreted by monocytes and macrophages and can be secreted by $\mathrm{T}$ cells. It is chemotactic and activates macrophages to induce secretion of TNF, IL-6, and IL-1 and it enhances killing as well. CCL3 can also be chemotactic for eosinophils, B and CD8 T cells. CCL4 (MIP-1 $\beta$ ) is primarily chemotactic for lymphocytes and monocytes. A single dose of lipopolysaccharide(LPS) given to healthy persons has been shown to cause an increase in both CCL3 and CCL4, which peaks approximately 2 hours after LPS is administered. Patients with bacterial meningitis have an increase of CCL4 in the cerebral spinal fluid. ${ }^{80}$

LBP is mainly synthesized in the liver, but it can also be synthesized by epithelial and muscle cells as an acute-phase protein. It binds LPS of gram-negative bacteria to CD14 as well as TLRs, and modulates the microbial-induced activation of the inflammatory host response. Levels of LPB peak within 6 to 8 hours after an acute infection. It has better sensitivity and specificity for detecting sepsis than LPS-soluble, PCT, and CD14 complexes in early onset sepsis. But it is as equally effective as CRP in detecting sepsis in neonates older than 48 hours. Although LPB has a promising potential, further research is required for neonatal sepsis. ${ }^{81}$

Serum amyloid A (SAA) is an acute-phase protein regulated by the proinflammatory cytokines (IL-1, IL-6, TNF $\alpha$ ). It is an apolipoprotein produced in the liver as well as derived from a variety of other tissues such as monocytes, endothelial cells, and smooth muscle cells. There is a significant increase in SAA levels from 8 to 24 hours after the onset of sepsis, and it was shown that SAA had better diagnostic accuracy than CRP in septic evaluation in neonatal early onset sepsis. Especially the des-arginine variant of SAA holds promise as a marker of acute and chronic inflammation. ${ }^{82}$

IFN- $\gamma$-IP-10 is induced by IFN- $\gamma$ in many types of cells including monocytes and lung epithelial cells. IP-10, also named CXCL10, is a potent chemokine for activated T lymphocytes and regulates cell proliferation, apoptosis, and adhesion molecule expression. ${ }^{83}$ IP-10 level was higher in neonates with sepsis and necrotizing enterocolitis than in neonates who had only necrotizing enterocolitis. ${ }^{84}$

High mobility group box 1 (HMGB1) is a chromatin protein localized in the nucleus and the cytoplasm. Cytokines TNF- $\alpha$ and IFN- $\gamma$ stimulate macrophages to release HMGB1, while endotoxin induces late release of HMGB1. In animal models, HMGB1 can be detected in serum 8 hours after endotoxemia, and plateau levels are archived from 16 to 32 hours. ${ }^{85}$ Antibodies (anti-HMGB1) can reduce endotoxininduced acute lung injury and increase survival. In humans, HMGB1 were elevated in patients with surgical sepsis and in those with DIC. Also, it was significantly higher in septic nonsurvivors versus survivors. ${ }^{86,87}$

Triggering receptor expressed on myeloid cells-1 (TREM1) belongs to the immunoglobulin superfamily and stimulates the release of cytokines such as TNF- $\alpha$ and IL-1 $\beta$. Because it is not easily identified, its soluble form (sTREM) is a better option for a biomarker in sepsis. sTREM is higher in patients with septic shock and reaches peak levels at approximately 2 hours after infectious exposure. Its sustained elevation appears to predict a poor outcome. All this makes it an accurate marker of sepsis. ${ }^{88,89}$

Several other reactants show potential and have been studied as biomarkers of sepsis. Some of these biomarkers are $\alpha-1$ antitrypsin, fibronectin, lactoferrin, neopterin, and haptoglobin. Very few potential biomarkers reach the true biomarker stage. Although PCT is currently the most promising diagnostic biomarker for sepsis, recent evidence suggested that IL-8 can be used to stratify children with septic shock. Recently, great efforts have been made to develop a multibiomarkerbased sepsis risk model for predicting illness severity and outcome for children with septic shock. ${ }^{90}$ IL-8 and CCL4 are clinically appealing because of their relative simplicity, but both stratification biomarkers have insufficient positive predictive values, sensitivities, and specificities to develop a comprehensive pediatric septic shock stratification tool. ${ }^{41,91}$ The biological response during septic shock is exceedingly complex, and it is possible that a multibiomarker stratification strategy can more comprehensively meet these needs. ${ }^{92}$ Numerous acute-phase 
proteins potentially may be biomarkers for sepsis, but none has been routinely used. The goal of the final model will be to predict illness severity and outcome of pediatric patients with septic shock. It will provide a decision-making and stratification tool for the care of children with septic shock.

\section{Conclusion}

Numerous studies have explained many different pathophysiological processes involved in sepsis and have revealed an important regulatory role of pro- and anti-inflammatory cytokines. But despite a great number of clinical studies, cytokines pathophysiology is still incompletely understood, and specific anticytokine treatments have not been successful in clinical trials. This is due to the fact that sepsis is a complex and dynamic process that involves excessive inflammatory and immune response. A small number of researches have been conducted in pediatric sepsis using multiple markers. The best approach to the diagnosis of sepsis is the combination of different biomarkers because the multiple indicators of infection can improve specificity and sensitivity of the whole assay.

\section{References}

1 Rittirsch D, Flierl MA, Ward PA. Harmful molecular mechanisms in sepsis. Nat Rev Immunol 2008;8(10):776-787

2 Wen $\mathrm{AQ}, \mathrm{Gu}$ W, Wang J, et al. Clinical relevance of IL-1beta promoter polymorphisms $(-1470,-511$, and -31$)$ in patients with major trauma. Shock 2010;33(06):576-582

3 Zhang AQ, Pan W, Gao JW, et al. Associations between interleukin1 gene polymorphisms and sepsis risk: a meta-analysis. BMC Med Genet 2014; 15:8

4 Watanabe E, Buchman TG, Hirasawa H, Zehnbauer BA. Association between lymphotoxin-alpha (tumor necrosis factor-beta) intron polymorphism and predisposition to severe sepsis is modified by gender and age. Crit Care Med 2010;38(01):181-193

5 Schulte W, Bernhagen J, Bucala R. Cytokines in sepsis: potent immunoregulators and potential therapeutic targets-an updated view. Mediators Inflamm 2013;2013:165974

6 Blackwell TS, Christman JW. Sepsis and cytokines: current status. Br J Anaesth 1996;77(01):110-117

7 de Jong HK, van der Poll T, Wiersinga WJ. The systemic proinflammatory response in sepsis. J Innate Immun 2010;2(05): 422-430

8 Balk R. Roger C. Bone, MD and the evolving paradigms of sepsis. Contrib Microbiol 2011;17:1-11

9 Cohen J. The immunopathogenesis of sepsis. Nature 2002;420 (6917):885-891

10 van der Poll T, van Deventer SJ. Cytokines and anticytokines in the pathogenesis of sepsis. Infect Dis Clin North Am 1999;13(02): 413-426, ix

11 Berner R, Niemeyer CM, Leititis JU, et al. Plasma levels and gene expression of granulocyte colony-stimulating factor, tumor necrosis factor-alpha, interleukin (IL)-1beta, IL-6, IL-8, and soluble intercellular adhesion molecule-1 in neonatal early onset sepsis. Pediatr Res 1998;44(04):469-477

12 Parameswaran N, Patial S. Tumor necrosis factor- $\alpha$ signaling in macrophages. Crit Rev Eukaryot Gene Expr 2010;20(02):87-103

13 Lewis M, Tartaglia LA, Lee A, et al. Cloning and expression of cDNAs for two distinct murine tumor necrosis factor receptors demonstrate one receptor is species specific. Proc Natl Acad Sci U S A 1991;88(07):2830-2834
14 Shannon E, Noveck R, Sandoval F, Kamath B, Kearney M. Thalidomide suppressed interleukin- 6 but not tumor necrosis factoralpha in volunteers with experimental endotoxemia. Transl Res 2007; 150(05):275-280

15 Prashant A, Vishwanath P, Kulkarni P, et al. Comparative assessment of cytokines and other inflammatory markers for the early diagnosis of neonatal sepsis-a case control study. PLoS One 2013; 8(07):e68426

16 Bhatia M, Moochhala S. Role of inflammatory mediators in the pathophysiology of acute respiratory distress syndrome. J Pathol 2004;202(02):145-156

17 van der Poll T, Büller HR, ten Cate H, et al. Activation of coagulation after administration of tumor necrosis factor to normal subjects. N Engl J Med 1990;322(23):1622-1627

18 Schouten M, Wiersinga WJ, Levi M, van der Poll T. Inflammation, endothelium, and coagulation in sepsis. J Leukoc Biol 2008; 83(03):536-545

19 Silveira RC, Procianoy RS. Evaluation of interleukin-6, tumour necrosis factor- $\alpha$ and interleukin- $1 \beta$ for early diagnosis of neonatal sepsis. Acta Paediatr 1999;88(06):647-650

20 Duncombe G, Veldhuizen RA, Gratton RJ, Han VK, Richardson BS. IL-6 and TNFalpha across the umbilical circulation in term pregnancies: relationship with labour events. Early Hum Dev 2010;86(02):113-117

21 O'Neill LA. The interleukin-1 receptor/Toll-like receptor superfamily: 10 years of progress. Immunol Rev 2008;226(01):10-18

22 Smith K, Bigham MT. Biomarkers in pediatric sepsis. Open Inflamm J 2011;4:24-30

23 Loisa P, Rinne T, Laine S, Hurme M, Kaukinen S. Anti-inflammatory cytokine response and the development of multiple organ failure in severe sepsis. Acta Anaesthesiol Scand 2003;47(03):319-325

24 Okusawa S, Gelfand JA, Ikejima T, Connolly RJ, Dinarello CA. Interleukin 1 induces a shock-like state in rabbits. Synergism with tumor necrosis factor and the effect of cyclooxygenase inhibition. J Clin Invest 1988;81(04):1162-1172

25 Dinarello CA. Infection, fever, and exogenous and endogenous pyrogens: some concepts have changed. J Endotoxin Res 2004; 10(04):201-222

26 Conte D, Holcik M, Lefebvre CA, et al. Inhibitor of apoptosis protein cIAP2 is essential for lipopolysaccharide-induced macrophage survival. Mol Cell Biol 2006;26(02):699-708

27 Shimaoka M, Park EJ. Advances in understanding sepsis. Eur J Anaesthesiol Suppl 2008;42(42):146-153

28 Gårdlund B, Sjölin J, Nilsson A, Roll M, Wickerts CJ, Wretlind B. Plasma levels of cytokines in primary septic shock in humans: correlation with disease severity. J Infect Dis 1995;172(01): 296-301

29 Ohlsson K, Björk P, Bergenfeldt M, Hageman R, Thompson RC. Interleukin-1 receptor antagonist reduces mortality from endotoxin shock. Nature 1990;348(6301):550-552

30 Choy E. Understanding the dynamics: pathways involved in the pathogenesis of rheumatoid arthritis. Rheumatology (Oxford) 2012;51(05, Suppl 5):v3-v11

31 Kapoor M, Martel-Pelletier J, Lajeunesse D, Pelletier JP, Fahmi H. Role of proinflammatory cytokines in the pathophysiology of osteoarthritis. Nat Rev Rheumatol 2011;7(01):33-42

32 Jawień J. New insights into immunological aspects of atherosclerosis. Pol Arch Med Wewn 2008;118(03):127-131

33 Park JY, Pillinger MH. Interleukin-6 in the pathogenesis of rheumatoid arthritis. Bull NYU Hosp Jt Dis 2007;65(01, Suppl 1): S4-S10

34 Scheller J, Rose-John S. Interleukin-6 and its receptor: from bench to bedside. Med Microbiol Immunol (Berl) 2006;195(04):173-183

35 Kishimoto T. The biology of interleukin-6. Blood 1989;74(01):1-10

36 Tasci Y, Dilbaz B, Uzmez Onal B, et al. The value of cord blood interleukin-6 levels for predicting chorioamnionitis, funisitis and neonatal infection in term premature rupture of membranes. Eur J Obstet Gynecol Reprod Biol 2006;128(1-2):34-39 
37 Remick DG, Bolgos G, Copeland S, Siddiqui J. Role of interleukin-6 in mortality from and physiologic response to sepsis. Infect Immun 2005;73(05):2751-2757

38 Bloos F, Reinhart K. Rapid diagnosis of sepsis. Virulence 2014; 5(01):154-160

39 Takala A, Jousela I, Jansson SE, et al. Markers of systemic inflammation predicting organ failure in community-acquired septic shock. Clin Sci (Lond) 1999;97(05):529-538

40 Calfee CS, Thompson BT, Parsons PE, Ware LB, Matthay MA, Wong HR. Plasma interleukin-8 is not an effective risk stratification tool for adults with vasopressor-dependent septic shock. Crit Care Med 2010;38(06):1436-1441

41 Wong HR, Cvijanovich N, Wheeler DS, et al. Interleukin-8 as a stratification tool for interventional trials involving pediatric septic shock. Am J Respir Crit Care Med 2008;178(03):276-282

42 Wong HR, Shanley TP, Sakthivel B, et al. ; Genomics of Pediatric SIRS/Septic Shock Investigators. Genome-level expression profiles in pediatric septic shock indicate a role for altered zinc homeostasis in poor outcome. Physiol Genomics 2007;30(02): 146-155

43 Standage SW, Wong HR. Biomarkers for pediatric sepsis and septic shock. Expert Rev Anti Infect Ther 2011;9(01):71-79

44 Fan Y, Yu JL. Umbilical blood biomarkers for predicting earlyonset neonatal sepsis. World J Pediatr 2012;8(02):101-108

45 Bhandari V. Effective biomarkers for diagnosis of neonatal sepsis. J Pediatric Infect Dis Soc 2014;3(03):234-245

46 Silveira RC, Fortes Filho JB, Procianoy RS. Assessment of the contribution of cytokine plasma levels to detect retinopathy of prematurity in very low birth weight infants. Invest Ophthalmol Vis Sci 2011;52(03):1297-1301

47 Jones LL, Vignali DA. Molecular interactions within the IL-6/IL-12 cytokine/receptor superfamily. Immunol Res 2011;51(01):5-14

48 Howard M, Muchamuel T, Andrade S, Menon S. Interleukin 10 protects mice from lethal endotoxemia. J Exp Med 1993;177(04): 1205-1208

$49 \mathrm{Ng}$ PC, Lam HS. Biomarkers for late-onset neonatal sepsis: cytokines and beyond. Clin Perinatol 2010;37(03):599-610

50 Zeng L, Gu W, Chen K, et al. Clinical relevance of the interleukin 10 promoter polymorphisms in Chinese Han patients with major trauma: genetic association studies. Crit Care 2009;13(06):R188

51 Hazelzet JA, Kornelisse RF, van der Pouw Kraan TC, et al. Interleukin 12 levels during the initial phase of septic shock with purpura in children: relation to severity of disease. Cytokine 1997;9(09):711-716

52 Estaquier J, Idziorek T, Zou W, et al. T helper type 1/T helper type 2 cytokines and T cell death: preventive effect of interleukin 12 on activation-induced and CD95 (FAS/APO-1)-mediated apoptosis of CD4+ T cells from human immunodeficiency virus-infected persons. J Exp Med 1995;182(06):1759-1767

53 Weighardt $\mathrm{H}$, Heidecke CD, Westerholt A, et al. Impaired monocyte IL-12 production before surgery as a predictive factor for the lethal outcome of postoperative sepsis. Ann Surg 2002;235(04): 560-567

54 Sherwin C, Broadbent R, Young S, et al. Utility of interleukin-12 and interleukin-10 in comparison with other cytokines and acute-phase reactants in the diagnosis of neonatal sepsis. Am J Perinatol 2008;25(10):629-636

55 Cui YL, Wang B, Gao HM, et al. Interleukin-18 and miR-130a in severe sepsis patients with thrombocytopenia. Patient Prefer Adherence 2016;10:313-319

56 Kingsmore SF, Kennedy N, Halliday HL, et al. Identification of diagnostic biomarkers for infection in premature neonates. Mol Cell Proteomics 2008;7(10):1863-1875

57 Bender L, Thaarup J, Varming K, Krarup H, Ellermann-Eriksen S, Ebbesen F. Early and late markers for the detection of early-onset neonatal sepsis. Dan Med Bull 2008;55(04):219-223

58 Blobe GC, Schiemann WP, Lodish HF. Role of transforming growth factor $\beta$ in human disease. N Engl J Med 2000;342(18):1350-1358
59 Wan YY, Flavell RA. TGF- $\beta$ and regulatory T cell in immunity and autoimmunity. J Clin Immunol 2008;28(06):647-659

60 Kumar A, Kumar A, Paladugu B, Mensing J, Parrillo JE. Transforming growth factor- $\beta 1$ blocks in vitro cardiac myocyte depression induced by tumor necrosis factor- $\alpha$, interleukin- $1 \beta$, and human septic shock serum. Crit Care Med 2007;35(02):358-364

61 Perrella MA, Hsieh CM, Lee WS, et al. Arrest of endotoxin-induced hypotension by transforming growth factor beta1. Proc Natl Acad Sci U S A 1996;93(05):2054-2059

62 Knapp S, Thalhammer F, Locker GJ, et al. Prognostic value of MIP-1 $\alpha$, TGF- $\beta 2$, sELAM- 1 , and sVCAM-1 in patients with gram-positive sepsis. Clin Immunol Immunopathol 1998;87(02):139-144

63 Seder RA, Paul WE, Davis MM, Fazekas de St Groth B. The presence of interleukin 4 during in vitro priming determines the lymphokine-producing potential of CD4+ T cells from $\mathrm{T}$ cell receptor transgenic mice. J Exp Med 1992;176(04):1091-1098

64 Opal SM, DePalo VA. Anti-inflammatory cytokines. Chest 2000; 117(04):1162-1172

$65 \mathrm{Wu} \mathrm{HP}, \mathrm{Wu} \mathrm{CL}$, Chen CK, et al. The interleukin-4 expression in patients with severe sepsis. J Crit Care 2008;23(04):519-524

66 Weber GF, Chousterman BG, He S, et al. Interleukin-3 amplifies acute inflammation and is a potential therapeutic target in sepsis. Science 2015;347(6227):1260-1265

67 Lam HS, Wong SP, Cheung HM, et al. Early diagnosis of intraabdominal inflammation and sepsis by neutrophil CD64 expression in newborns. Neonatology 2011;99(02):118-124

68 Rudensky B, Sirota G, Erlichman M, Yinnon AM, Schlesinger Y. Neutrophil CD64 expression as a diagnostic marker of bacterial infection in febrile children presenting to a hospital emergency department. Pediatr Emerg Care 2008;24(11):745-748

69 Groselj-Grenc M, Ihan A, Pavcnik-Arnol M, Kopitar AN, GmeinerStopar T, Derganc M. Neutrophil and monocyte CD64 indexes, lipopolysaccharide-binding protein, procalcitonin and C-reactive protein in sepsis of critically ill neonates and children. Intensive Care Med 2009;35(11):1950-1958

70 Cid J, Aguinaco R, Sánchez R, García-Pardo G, Llorente A. Neutrophil CD64 expression as marker of bacterial infection: a systematic review and meta-analysis. J Infect 2010;60(05): 313-319

71 Markic J, Jeroncic A, Polancec D, et al. CD15s is a potential biomarker of serious bacterial infection in infants admitted to hospital. Eur J Pediatr 2013;172(10):1363-1369

72 Muller Kobold AC, Tulleken JE, Zijlstra JG, et al. Leukocyte activation in sepsis; correlations with disease state and mortality. Intensive Care Med 2000;26(07):883-892

73 Turunen R, Andersson S, Nupponen I, Kautiainen H, Siitonen S, Repo H. Increased CD11b-density on circulating phagocytes as an early sign of late-onset sepsis in extremely low-birth-weight infants. Pediatr Res 2005;57(02):270-275

74 Genel F, Atlihan F, Gulez N, et al. Evaluation of adhesion molecules CD64, CD11b and CD62L in neutrophils and monocytes of peripheral blood for early diagnosis of neonatal infection. World J Pediatr 2012;8(01):72-75

75 Mikkelsen ME, Miltiades AN, Gaieski DF, et al. Serum lactate is associated with mortality in severe sepsis independent of organ failure and shock. Crit Care Med 2009;37(05):1670-1677

76 Jansen TC, van Bommel J, Bakker J. Blood lactate monitoring in critically ill patients: a systematic health technology assessment. Crit Care Med 2009;37(10):2827-2839

77 Arnold RC, Shapiro NI, Jones AE, et al; Emergency Medicine Shock Research Network (EMShockNet) Investigators. Multicenter study of early lactate clearance as a determinant of survival in patients with presumed sepsis. Shock 2009;32(01):35-39

78 Jones AE, Shapiro NI, Trzeciak S, Arnold RC, Claremont HA, Kline JA; Emergency Medicine Shock Research Network (EMShockNet) Investigators. Lactate clearance vs central venous oxygen saturation as goals of early sepsis therapy: a randomized clinical trial. JAMA 2010;303(08):739-746 
79 Scott HF, Donoghue AJ, Gaieski DF, Marchese RF, Mistry RD. The utility of early lactate testing in undifferentiated pediatric systemic inflammatory response syndrome. Acad Emerg Med 2012; 19(11):1276-1280

80 Alder MN, Lindsell CJ, Wong HR. The pediatric sepsis biomarker risk model: potential implications for sepsis therapy and biology. Expert Rev Anti Infect Ther 2014;12(07):809-816

81 Pavcnik-Arnol M, Hojker S, Derganc M. Lipopolysaccharide-binding protein, lipopolysaccharide, and soluble CD14 in sepsis of critically ill neonates and children. Intensive Care Med 2007;33 (06):1025-1032

82 Arnon S, Litmanovitz I, Regev RH, Bauer S, Shainkin-Kestenbaum R, Dolfin T. Serum amyloid A: an early and accurate marker of neonatal early-onset sepsis. J Perinatol 2007;27(05):297-302

83 Neville LF, Mathiak G, Bagasra O. The immunobiology of interferon-gamma inducible protein $10 \mathrm{kD}$ (IP-10): a novel, pleiotropic member of the C-X-C chemokine superfamily. Cytokine Growth Factor Rev 1997;8(03):207-219

$84 \mathrm{Ng} \mathrm{PC}$, Li K, Chui KM, et al. IP-10 is an early diagnostic marker for identification of late-onset bacterial infection in preterm infants. Pediatr Res 2007;61(01):93-98

85 Sama AE, D'Amore J, Ward MF, Chen G, Wang H. Bench to bedside: HMGB1-a novel proinflammatory cytokine and potential therapeutic target for septic patients in the emergency department. Acad Emerg Med 2004;11(08):867-873
86 Yang H, Ochani M, Li J, et al. Reversing established sepsis with antagonists of endogenous high-mobility group box 1. Proc Natl Acad Sci U S A 2004;101(01):296-301

87 Hatada T, Wada H, Nobori T, et al. Plasma concentrations and importance of High Mobility Group Box protein in the prognosis of organ failure in patients with disseminated intravascular coagulation. Thromb Haemost 2005;94(05):975-979

88 Routsi C, Giamarellos-Bourboulis EJ, Antonopoulou A, et al. Does soluble triggering receptor expressed on myeloid cells-1 play any role in the pathogenesis of septic shock? Clin Exp Immunol 2005; 142(01):62-67

89 Gibot S, Cravoisy A, Kolopp-Sarda MN, et al. Time-course of sTREM (soluble triggering receptor expressed on myeloid cells)-1, procalcitonin, and C-reactive protein plasma concentrations during sepsis. Crit Care Med 2005;33(04):792-796

90 Kaplan JM, Wong HR. Biomarker discovery and development in pediatric critical care medicine. Pediatr Crit Care Med 2011; 12(02):165-173

91 Nowak JE, Wheeler DS, Harmon KK, Wong HR. Admission chemokine (C-C motif) ligand 4 levels predict survival in pediatric septic shock. Pediatr Crit Care Med 2010;11(02): 213-216

92 Wong HR, Cvijanovich N, Lin R, et al. Identification of pediatric septic shock subclasses based on genome-wide expression profiling. BMC Med 2009;7:34 